\title{
An experience at the epicenter: encounter with a traditional healer
}

\author{
Shristi Rijal ${ }^{*}$, Dipika Neupane ${ }^{1}$ \\ ${ }^{1}$ Maharajgunj Medical Campus, Institute of Medicine, Tribhuvan University, Kathmandu, Nepal
}

Received:

31 January 2016

Revised:

25 February 2016

Accepted:

11 March 2016

\section{*Correspondence: shristirijal35@gmail.com Maharajgunj Medical Campus, Institute of Medicine, Tribhuvan University, Kathmandu, Nepal.}

After the earthquake of April 25, 2015 in Nepal, the situation at Barpak, the epicenter was heart-rending. 70 people in Barpak had lost their lives and 178 were seriously injured after the disaster (1). International Medical Corps, an international organization where we were working as hygiene promoter, provided us an opportunity to respond to the epicenter. This experience enlightened us about the role of traditional healers in rural Nepal and the possibilities of incorporating them in the health system.

Pokheri, ward number 1 of Barpak, was a remote village having settlement in the slope of the hill. The closely built houses in the village were destroyed by the shake making it difficult to segregate one's own property; it looked like a huge pile of debris. People were living in temporary houses with scarcity of food and hygiene practices. They had to walk for two hours to reach the health post for primary health care services; health workers were unavailable in the village.

After a short diagnosis in the village as hygiene promoters for IMC, we gathered some children for health promotion; taught them about personal hygiene and sanitation encouraging them to wash their hands and faces with soap and water. The children seemed distressed - perhaps due to sufferings brought by the earthquake.

The following evening, we heard sound of a continuous beating nearby our tent. In frequent intervals, we used to hear some murmur which was coming from a temporary shelter nearby. It was the sound of a traditional healer, Jhankri treating a child. Being students of public health, it naturally attracted our concern. We went to the house. In a dimly lit room, 7-8 people were sincerely watching the Jhankri. A child--one of the children we taught about hygiene earlier that day-- was sleeping in a bed. According to his mother, he was not eating properly for the last 3 days, seemed lazy and was complaining of headache.

The constant sound of hitting the Dhyangro (drum) was hypnotic. Jhankri was murmuring in Gurung language. One of the family members translated it to us. He was asking Devi (goddess) to send his Saato (presence of mind(2)) back, which they thought was lost. The ritual was quite long. Soon they were going to sacrifice a rooster. But as it was getting dark, we returned back to our tent and slept peacefully--hearing the mild hypnotic sound. The ritual must have continued till the midnight.

On the second day, we started home-to-home health sanitation and hygiene promotion program. In that small village, about 5-7 children had diarrhea. They used to defecate on barren lands nearby their houses. To conscientize them about the health hazards of open defecation, we asked the people to guide us to the place where the children defecated. Observing flies all around the place including their kitchens, they understood what we were trying to explain. We sprayed phenyl in those places, taught them to use phenyl and handed a bottle for future use. They didn't know that diarrhea was a communicable disease nor had any idea of treating it. During hygiene promotion, we reached the house of the Jhankri, who was treating the little boy the previous day. For the villagers, he was the only healer. But, he himself was unaware about health and disease transmission. When we informed him about the disease transmission he was convinced and expressed motivation to communicate his learning with the villagers.

The third day, we saw the same child, hale and hearty he was, playing with his siblings. We had never imagined that the child was so cheerful. He was not given any allopathic treatment, but he healed quickly. Though we were not sure about the illness he had and how he recovered, we ruminated on the total sequence of events. The circumstance changed after the devastating earthquake. In that agonizing situation, they were traumatized as well as subjected to unhygienic behaviors. We believe that our hygiene and sanitation program was an assistance for them to return them to hygienic environment and behaviors, to an extent. On the other hand, Jhankri might have healed their mental agony, with his hypnotic murmur and sound of hitting Dhyangro.

This experience broadened our view about the role of traditional healer in rural community. Nepal is facing shortage of health workers. Doctor and nurses per 1000 population is 0.67 in Nepal, while WHO targets 2.3 doctors, nurses and midwives per 1000 population (3). In addition, where health care cost is beyond the paying capacity of economically vulnerable group, the role of traditional healers in pacifying the situation is noteworthy. Traditional healers who are socio-culturally and emotionally attached to the people can meet the expectations of the patient. Rural people mostly seek traditional healers to treat mental fear, mood swings, fatigues, etc. Often successful in treating the patient, they help to restore social relation of the patient, which otherwise would have been stigmatizing (2). Traditional healers can be incorporated in the 
health system as a portal for referral as well. Training conduction to strengthen the role of traditional healer in community health was proved beneficial when the number of referral to health post and sub health post increased after the training (4). In the same way, by bringing traditional healers to the foreground, teaching them about health and disease they can be the helping hands to improve the health situation for the population.

\section{References}

1. District Health Office. Earthquake Report. Gorkha. 2072. Print

2. Kohrt BA, Harper I. Navigating diagnoses: understanding mind-body relations, mental health, and stigma in Nepal. Cult Med Pychiatry 2008;32(4):462-91 doi: 10.1007/s11013-008-9110-6.

3. Ministry of Health and Population, Human Resources for Health: Nepal Country Profile. In: Group HTW, ed.: 2013. Available at: http://www.nhssp.org.np/ human_resources/HRH\%20profile\%20(QA).pdf

4. Poudyal AK, Jimba M, Murakami I, et al. A traditional healers' training model in rural Nepal: strengthening their roles in community health. Trop Med Int Health. 2003;8(10):956-60. doi: 10.1046/j.1365-3156.2003.01094.x. 